\title{
Child protection vocabulary in the Children Act 1989: Power, ambiguity and heterogeneity
}

\author{
iD Panagiotis Pentaris ${ }^{1}$ and Abiola Oresanya ${ }^{1}$ \\ ${ }^{1}$ School of Human Sciences \& institute for Lifecourse Development, University of Greenwich
}

Received 6 September 2021

Accepted for publication 2 November 2021

Published 18 December 2021

\begin{abstract}
An established legislative framework in Child Protection has been in effect in the last few decades. Yet, the responsibility of the Law and the Child Protection System is to continuously explore social needs, as they change, transform or new ones are introduced to adapt to the circumstances in the attempts to safeguard and protect children. This paper is not focusing on those adaptations; it draws on this responsibility to argue that in an ever-changing world, wherein needs and demands are shifting, Child Protection Vocabulary needs to be more explicit and adaptive to those changes. Vocabulary like 'best interest', 'resilience', 'power', and 'vulnerability' are commonplace in child protection legislation, regulation, policy and practice. That said, the question of interpretation is always of concern; how are the varied agencies, stakeholders, authorities, groups, and individuals approaching safeguarding and child protection when the heterogeneity of the language used is ever-increasing? This paper provides a conceptual content analysis of Child Protection Vocabulary found in the Children Act 1989. The analysis will be drawing on the amendments in Children Act 2004, as well as the Children and Social Work Act 2017, but will preserve its focus on the Children Act 1989 as the foundation for the contemporary Child Protection System. Implications of the findings are provided at the end.
\end{abstract}

Keywords: child protection, Children Act 1989, child protection vocabulary, safeguarding, welfare

\section{Introduction}

Laws surrounding child cruelty have been in place since the 1880s, however the death of 7-year-old Maria Colwell in 1973 led to the modern child protection system. Yet, it took over thirty years before agencies were required by law - Children Act 2004 - to disclose and exchange information about a child. The Child Protection System put in place in 1973 was updated in 1984 following inquiries into children's deaths including that of 4-year-old Jasmine Beckford. The Child Protection System was established in a legislative framework in England and Wales in 1989, in the Children Act 1989, while in 1990, the UK signed the United Nations Convention on the Rights of the Child (UNCRC), which further solidified the rights of children for survival, growth, participation and protection, complementing, thus, the child protection principles of the Children Act 1989.

Subsequent studies about the effectiveness of the Children Act 1989 (Aldgate and Stratham, 2001) have found that the
Act has helped refine definitions of safeguarding and influenced local authorities to put more emphasis on promoting the welfare of children in need. The Act has also refined definitions 'to children's participation in decisionmaking, working in partnerships with parents, providing effective social services and the value of interdisciplinary working between services' (Aldgate and Stratham, 2001, p.1). Overall, the Children Act 1989 is a sound piece of legislation and provides a robust framework for the delivery and monitoring of services in England and Wales, but Part 3 of the Act was replaced with Part 6 for Wales since 2014. Safeguarding and child welfare are key principles that the Act has enabled local governments to take into account more systematically, while children's rights of participation in services are promoted (also see Cooper and Whittaker, 2014). Albeit its strengths and impact, the Act has not always presented clearly. Some sections have been problematic, primarily because of the lack of clarity in their intentions or 
lack of resources to enable the provisions to be realised (Aldgate and Stratham, 2001).

Aldgate and Stratham (2001, p.149) highlighted that:

'The Children Act 1989 is alive and generally well but needs some remedial attention in specific areas. Overall, we have come a long way in a short time. Much has been accomplished and much has been learned from successes and mistakes. There has been a rethinking of practice that has made a difference to the lives of many children in need and their families. Now the task is to ensure that, across England and Wales, all children in need receive consistently good and effective services to safeguard them and promote their welfare'.

Indeed, and at the time, the Act provided a firm platform upon which to build a strong Child Protection System, which continues today, notwithstanding changes along the way. In 2000 , following abuse and neglect by a family member and their partner, Victoria Climbié, an 8-year-old child, was found dead. This death led to the Lord Laming's report (2003), which examined the failings of the Child Protection System to prevent such situations. Following this report, the Children Act 1989 saw changes introduced with the Children Act 2004. This Act established a Children's Commissioner in England, introduced the Local Safeguarding Children's Boards (LSCBs) in England and Wales, and provided that local authorities in England would need to appoint a director and an elected lead member of children's services. The latter was in the need to assign accountability to the delivery of the services.

A further event - the death of 1-year-old Peter Connelly (popularised in the media as 'Baby P') by his mother, her boyfriend and the latter's brother - led to additional amendments and provisions in the Child Protection System. The event led to the second and influential Lord Laming report (2009). The report made 58 recommendations of which many relied on inter-agency communication and collaborations. That said, working together guidance documents became available and policies started highlighting the responsibility of agencies to abide by this principle. Further, in 2010, the Secretary of State for Education commissioned Professor Eileen Munro to undertake an independent review of child protection in England. The Munro review (2011) highlighted then that child protection in England was found to be highly bureaucratised and lacking inter-agency practice. The Munro report, as well as the independent review on child sexual exploitation (Klonowski, 2013) led to a new version of the Working Together to Safeguard Children (Department for Education, 2013; 2018).
Further failures recorded in the Child Protection System include those reported in the Independent Inquiry into Child Sexual Abuse in England and Wales (IICSA, 2018), which provided additional evidence of the lack of resources, interand intra-agency communications, and appropriate language, all of which influence institutional capacity to protect children and promote their wellbeing.

From the brief list of changes above, it becomes quickly clear that a common barrier to effective child protection measures is inter-agency communication, with an emphasis on communication. Even though different reports highlight the need for information flow, which has been found to be problematic (Thompson, 2016). However, information flow is not purely referring to the sharing of updates between agencies, but also between families and agencies (Featherstone, Morris and White, 2014), while the issue of language is critical (Munro, 2019).

This paper's intent is neither to examine the ways in which agencies and families interpret child protection and safeguarding law, nor to investigate how the language in such legislation has changed over time. Yet, by referring to the few milestones of child protection in England and Wales above, this introduction sets the scene for the following suspicion. If, for over 50 years, the Child Protection System is continuously recognised with institutional failures on the grounds of communication between and within agencies, then perhaps the issue is not the willingness to share the information, but the way legislation is interpreted by separate entities. If the interpretation of the provisions of the Children Act 1989 differ between those that are required to work together to safeguard children and promote wellbeing, then possibly the expectations and responsibilities of each of the parties are interpreted differently, too.

This paper tentatively takes a first step into exploring conceptually the language used in the Children Act 1989, but with consideration of the Children Act 2004 and the Children and Social Work Act 2017 - the latter adds to the safeguarding principles and provisions for children and solidifies the new regulator of social workers in England. By doing so, it identifies areas where research can further advance and benefit future initiatives about overcoming the shortcomings of the Child Protection System.

\section{Methodology}

This study is a conceptual content analysis of identified language in the Children Act 1989 with reference to the meanings, contexts and intentions contained in the vocabulary used (Prasad, 2008). The process borrowed from Erlingsson and Brysiewicz (2017) and the six-phase analysis leading to higher levels of abstraction. These steps include meaning unit, 
condensed meaning units, code, category, theme, and overarching theme. The ultimate aim is the identification of latent meanings. Specifically, the steps in Figure 1 were followed.

\subsection{Search criteria}

The initial search in the databases yielded 17,254 journal articles, using the Boolean indicator 'AND' with the key words 'ethnic minorities', 'help seeking', 'mental health' and 'mental illness'. These were systematically reduced by applying the following limiters: studies between the years 2008 and $2018(n=7,964)$, peer-reviewed and research papers $(n=7,065)$, UK-based studies $(n=1,464)$, empirical studies and the addition of the keyword 'spirituality' due to the prevalence of faith and religion in the articles $(n=79)$.

Moreover, seven further articles were sourced from searching the 'Social Work Online' database and the 'Google Scholar' search engine. There were three more articles found by snowballing which brought the grand total to 89 articles.

Figure 1. Content analysis: from lower to higher levels of abstraction

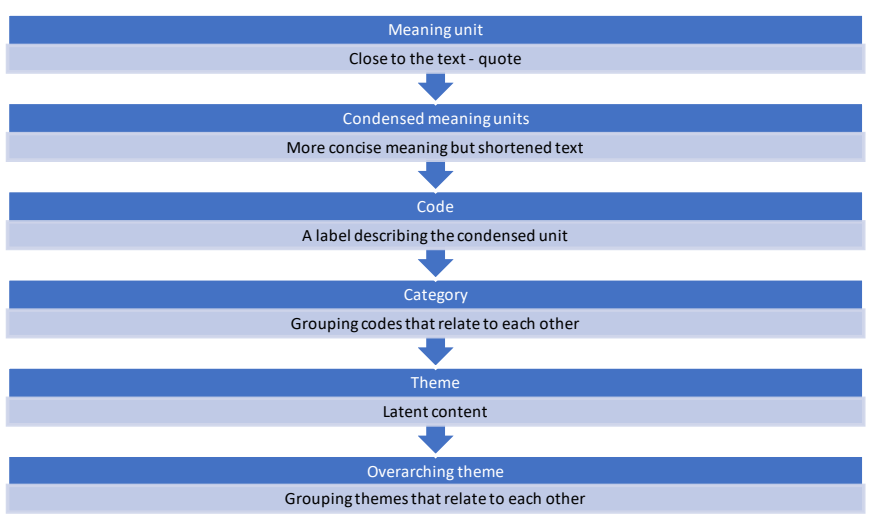

In addition, this examination draws on linguistic analysis, which manifests on many levels, and this study does not employ methods of lexical and syntactic analysis, as its aim is not an analysis of the frequency of lexico-grammatical features (Bhatia, 1993) in the Children Act 1989, the 2004 amendments and the Children and Social Work Act 2017. This study is concerned with both content and written discourse, thus borrows from Swales' (1990) genre analysis to identify the various moves in the sections of the Children Act 1989 and complements the content analysis that seeks to examine the conceptual understanding of the language used in the Act, but only of specific terms. The combination of these methods assists with not only identifying certain genres as themes but developing or recognising developed significant patterns of meaning.

First, genre analysis is described as an examination of categories of discourse. Swales (1990, p.33) points out that the term genre refers to 'a distinctive category of discourse of any type, spoken or written, with or without literary aspirations'. This study approaches the concept 'genres' as 'types or classes of cultural objects defined around criteria for class membership' (Martín-Martín, 2003, p.157). In other words, this analysis considers language in the sub-context of legislation (e.g. different sections with different focus) and classifies it conceptually.

Construct validity was ensured by following Yin's (1984) steps for case study research. Analysis was validated by reviewing interpretations of concepts and codes in turn, which led to refinement and final formulation of the themes. The final list of themes was scrutinised by both authors and an external consultant to ensure consistency, clarity and identify overarching themes, where applicable.

\subsection{Documents and vocabulary}

The focus of this content analysis is the exploration of the vocabulary used in the Children Act 1989 and subsequent amendments in the Children Act 2004 and the Children and Social Work Act 2017. These are complementary documents classified as official documents deriving from the Government (Bryman, 2016) and providing the legislative framework of child protection and safeguarding in the UK (Children Act 1989 and Children Act 2004) and England (Children and Social Work Act 2017; partially aimed at children and family social work). The Children and Family Act 2014 was considered for inclusion in this analysis, too. This Act tried to amend terminologies and language to a more contemporary environment, though did not meet the inclusion criteria that identified Acts setting the framework for child protection.

The study does not analyse the full length of the legislative framework but focuses on vocabulary that is ambiguous and subject to interpretation in practice (also see Warner, 2015). The vocabulary that the analysis focuses on was selected based on the critical analysis of categorisation and accountability in child welfare by Hall, Slembrouck and Sarangi (2020) and the exploration of child protection through a humane lens (Featherstone, Morris and White, 2014). Further, thorough investigation of ambiguous language used in the Children Act 1989, which has been queried in research (e.g. Grey, 2009; Fraser, Galinsky and Richman, 1999) previously was taken into account for the purposes of this analysis.

Once the Children Act 1989, Children Act 2004, and Children and Social Work Act 2017 were read for the first time, vocabulary that was open to interpretation, by both investigators, was identified in the text (e.g. power). The initial reading focused on the words rather than word sense or context. This search yielded 29 terms (Table 1). 
Table 1. Vocabulary used in child protection and safeguarding legislation (number of times used in the Acts)

\begin{tabular}{|c|c|c|c|}
\hline & $\begin{array}{l}\text { Children } \\
\text { Act } 1989 \text { (n) }\end{array}$ & $\begin{array}{l}\text { Children } \\
\text { Act } 2004 \text { (n) }\end{array}$ & $\begin{array}{l}\text { Children and } \\
\text { Social Work Act } \\
2017(n)\end{array}$ \\
\hline Authority & 1093 & 272 & 175 \\
\hline Force & 1287 & 29 & 12 \\
\hline Children & 1977 & 522 & 263 \\
\hline Order & 1540 & 47 & 41 \\
\hline Services & 340 & 272 & 27 \\
\hline Provision* & 874 & 99 & 129 \\
\hline Functions & 153 & 161 & 5 \\
\hline Responsib* & 198 & 8 & 4 \\
\hline Power & 129 & 19 & 22 \\
\hline Enforcement & 115 & - & 4 \\
\hline Protection & 109 & 11 & 9 \\
\hline Welfare & 102 & 21 & 8 \\
\hline Duty & 98 & 12 & 18 \\
\hline Consent & 56 & 14 & 3 \\
\hline Liable & 38 & 6 & - \\
\hline Wishes & 34 & 7 & 3 \\
\hline Prohibition & 26 & 2 & - \\
\hline Safeguard* & 43 & 39 & 88 \\
\hline Rights & 14 & 19 & 8 \\
\hline Safety & 11 & 8 & 3 \\
\hline Harm & 31 & 7 & 3 \\
\hline Comply & 95 & 4 & 6 \\
\hline Empower* & 3 & - & - \\
\hline Control* & 30 & - & - \\
\hline Vulnerab* & 2 & 5 & - \\
\hline Involvement & 12 & - & - \\
\hline Suffer* & 40 & 2 & - \\
\hline Best interest & 8 & - & 3 \\
\hline Resilience & - & - & - \\
\hline
\end{tabular}

The documents were then uploaded to NVivo 12 for organisation and management. Once uploaded, the documents were reviewed for a second time, exploring the contextual relationship of the terms to the intents of the documents. Where the terms were redundant or derivatives, they merged together but their reference in the text was still analysed. Finally, 14 terms were included in this conceptual content analysis (inclusive of their derivatives) (Table 2).
Table 2. Terms considered in the content analysis (number of times used in the Acts)

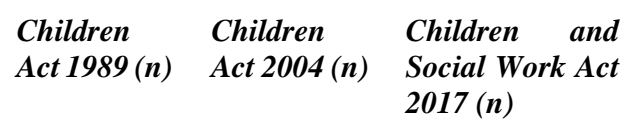

\begin{tabular}{l|lll}
\hline Authority & 1093 & 272 & 175 \\
Responsibilit & 198 & 8 & 4 \\
Power & 129 & 19 & 22 \\
Welfare & 102 & 21 & 8 \\
Duty & 98 & 12 & 18 \\
Wishes & 34 & 7 & 3 \\
Rights & 14 & 19 & 8 \\
Harm & 31 & 7 & 3 \\
Empower & 3 & - & - \\
Control & 30 & - & - \\
Vulnerab & 2 & 5 & - \\
Involvement & 12 & - & 3 \\
Best interest & 8 & - & 0 \\
Resilience & 0 & 0 &
\end{tabular}

\subsection{Data management and analysis}

NVivo 12 was used for the purposes of organising and managing the documents/data. NVivo is a software designed to assist with the analysis (often thematic) of qualitative data and provides a framework that organises the data in such ways that allow for the quantification of the findings, increasing validity and reliability (Jackson and Bazeley, 2019). With the use of NVivo, the vocabulary under investigation, and its conceptual meaning in the text, were coded, categorised and arranged into themes. Both authors reviewed the themes separately and negotiated those in collaboration before the final list of themes were decided.

\section{Findings}

This conceptual content analysis focused on 14 terms, 13 of which were found in the documents. The last term (i.e. 'resilience') was included in the linguistic search as well given its persistent usage in social work policy, practice and theory and in relation to child protection and safeguarding (see McFadden et al., 2019; Daniel, 2010). The term was not used or there was no reference to the concept of resilience across all three Acts. Further, the most found language in the legislation are 'authority', 'responsibility', 'power' and 'welfare', but not consistently across the three documents. For example, even though the Children Act 1989 refers to 'responsibility' often, the Children Act 2004 and the Children and Social Work Act 2017 only refer to the concept rarely (see 
Table 2). Similarly, the term 'harm' is not as often used to discuss child protection regulations in the Children Act 2004 and the Children and Social Work Act 2017 but is most popular in the Children Act 1989. Such tendencies show a shift in the ways in which similar or same situations and concepts are described; a point further discussed later in the paper.

Following the process of conceptual content analysis as described in the methodology, two grouping themes were identified to encapsulate the language used in the legislation (Figure 2). These are 'legitimate power and responsibility' and 'representation'. The former refers to language used to discuss governance and accountability, as they are negotiated and assigned to other parties (e.g. local government, parents, key workers). On the other hand, 'representation' refers to content that seeks to recognise what is of best interest, under what circumstances, and under whose authority.

Figure 2. Themes by vocabulary explored in the content analysis and coding

\begin{tabular}{|c|c|}
\hline \multirow{9}{*}{$\begin{array}{l}\text { Legitimate } \\
\text { power and } \\
\text { responsibility }\end{array}$} & Authority \\
\hline & Responsibilit* \\
\hline & Power \\
\hline & Duty \\
\hline & Right \\
\hline & Empower* \\
\hline & Control \\
\hline & Vulnerab* \\
\hline & Involvement \\
\hline \multirow[t]{4}{*}{ Representation } & Welfare \\
\hline & Wishes \\
\hline & Harm \\
\hline & Best interest \\
\hline
\end{tabular}

It is worth placing Table 2 and Figure 2 side-by-side. The language used to serve as a mediator and advocate on behalf of the wishes and welfare of children are not overly popular in the documents and often in passing and with varied meanings, as the next sections report. Specifically, the term 'welfare' is used more widely in the Children Act 1989 (n=102) but less so in the Children Act $2004(\mathrm{n}=21)$ and the Children and Social Work Act $2017(\mathrm{n}=8)$. Further, the terms 'wishes' and 'harm' only appear under an average of 14.7 and 13.4 times respectively and across the documents. Lastly, the term 'best interest' is only referred to in the Children Act $1989(n=8)$ and the Children and Social Work Act $2017(n=3)$.

To the contrary, the language used to develop governance, assign responsibility and highlight degrees of involvement of the different parties is used more often and with more emphasis. This is, of course, not irrational, yet it is debatable whether governance and regulations are underpinned by the concepts of representation in this legislation. The following sub-sections report on each of the terms explored and provide an analytical view on them, based on the concepts represented.

\subsection{Legitimate power and responsibility}

\subsubsection{Authority}

Child protection and safeguarding legislation uses the term 'authority' very often and always with reference to legitimate power or to describe an established agency that provides public services; for example, local authorities (in Children Act 1989 and Children and Social Work Act 2017) or children's services authorities (in Children Act 2004). The term is met often in the legislation, which identifies parents, agencies and children's services, the police, the court, and religious institutions as having authority over actions relating to the safeguarding of children and young people. Religion and denominational authority are only mentioned once (Children Act 1989, p.149, par.55(5)), stating that 'Where any trust deed relating to a controlled or assisted community home contains provision whereby a bishop or any other ecclesiastical or denominational authority has power to decide questions relating to religious instruction given in the home, no dispute which is capable of being dealt with in accordance with that provision shall be referred to the Secretary of State under this section'. In other words, denominational authority appears to be mentioned to complement the regulations about community homes and allocated responsibility among the agencies.

\subsubsection{Responsibility}

This term is used with reference to parental responsibility and assigned responsibility, yet the former can also be perceived as assigned responsibility by the legislation that dictates it. At large, the Children Act 1989 explores parental responsibility and details the varied scenarios in which parental responsibility is pertinent and what powers need to be exercised when such responsibilities are not upheld. The Act (i.e. Children Act 1989) is specifically assigning parental responsibility to mothers by default and fathers either by default or by acquisition. This separation is evident in sections 1 and 2 of the same Act, while consideration is given to the area of two mothers having parental responsibility of a single child, but the alternative of two fathers is not accounted for. Further, and in Children Act 2004 and Children and Social Work Act 2017, we come across very few mentions where the term refers to assigned responsibility, either to children's services, or to a professional within service organisations, which must assign them. For example, the Children and Social Work Act 20117, par.5(1) states that responsibility must be 
assigned to an individual professional within the school, and this professional will have overall educational responsibility for the organisation.

\subsubsection{Power}

Across the three documents, the concept of 'power' is used to refer to regulations that are either detailed in the Acts, or the assigned power of an agency or court to exercise those. In other words, the term 'power' refers to institutional power, and more specifically legitimate power. Yet, what is not considered in the Acts and the negotiation of powers is referent power - influence that relies on relationships, trust and respect. When examining the conceptions of 'best interest' and 'power' together in these pieces of legislation, the mismatch is apparent, or the intentions of the Acts misunderstood. To explain this further, best interest can only be achieved with careful consideration of the wishes, preferences and perspectives of those receiving the services, and this would only be achieved through the exercise of referent power (Martin, 1978). Yet, the only powers explored and regulated in the Acts appear to reflect legitimacy and authority. Legitimate power, nonetheless, does link up well with the notion of 'opinion' when considering best interest, yet in this case, only those with the power assigned to them by child protection and safeguarding legislation can determine best interest and always on behalf of others.

\subsubsection{Duty}

The term is used as a substitute to the term 'responsibility'. Duty, in child protection and safeguarding legislation, refers primarily to the statutory duties assigned to local and public services and organisations - the responsibility of local authorities and the inherent duty of care in the services.

\subsubsection{Right}

The terms power, authority, responsibility and rights are often used to describe the same content or are referring to the same concept. The term 'rights' is used to describe the areas wherein any party (e.g. parent, agency) has the right to exercise any specific power, or the authority to claim the right to do so. The interplay of the aforementioned terms is complex and essentially underlying the concept of legitimate power. In addition, in the Children Act 2004, the term is used to crossreference the legislation with the United Nations Convention on the Rights of the Child, as well as the underpinning principles in the Data Protection Act 1998 (c.29).

\subsubsection{Empower*}

The use of such language is purely aimed at referring to the empowerment of the court or a local authority to exercise the powers provided by the legislation. This term is only used three times in the Children Act 1989 and not at all in the Children Act 2004 and the Children and Social Work Act 2017, neither in relation to empowering services, nor in relation to empowering individuals.

\subsubsection{Control}

The term is only found in the Children Act 1989, but once in the Children Act 2004 when referring to Her Majesty's Stationery Office (UK). In the Children Act 1989, the term is used primarily to describe establishments that are regulated for accommodation in the community. Once in the Act does the term refer to 'parental control' (par.31(2bii)), when exploring care and supervision. The term is used to refer to the inability of parents to control their children which may result in risk of harm. Even though the term is not explicitly linked to the concept of inability or lacking capacity, the way it is negotiated in the Act carries a negative connotation, enabling further the idea of child protection characterising parents as villains.

\subsubsection{Vulnerab*}

The term 'vulnerable' and its variabilities were only found but a few times in the legislation. Specifically, twice in the Children Act 1989 and five times in the Children and Social Work Act 2017. On all occasions the term referred to either the Safeguarding Vulnerable Groups Act 2006 or the Protection of Vulnerable Groups (Scotland) Act 2007. The term is not used to describe populations that receive services or children and young people in need of protection.

\subsubsection{Involvement}

This term is not found in either the Children Act 2004 or the Children and Social Work Act 2017, but there are some mentions in the Children Act 1989. Those mentions purely discuss the involvement of a parent in a child's life (either direct or indirect $-1(2 \mathrm{~B})$ ) in setting provisions to safeguard the occasion where parental involvement is harmful or risking harm to the child. Alternatively, the language used here seems compatible with the conceptions of power, authority, regulation and responsibility, and it (i.e. language) sets ground rules that intend to regulate how safe the involvement of a parent is. Yet, what we are missing here, which is not uncommon in other parts of the legislation, is a descriptor or guidance about the criteria that deem involvement unsafe or risky. 


\subsection{Representation}

\subsubsection{Welfare}

All three legislations refer to the welfare of children and put emphasis on how provisions and services ought to be aligned and tailored towards this as the ultimate goal. Albeit the lack of explicit description of 'welfare' in the context of child protection within these pieces of legislation, the documents allude to the overall wellbeing of the child, inclusive of physical, mental and emotional wellbeing. What is consistently missing from these discussions and the way language is used in child protection and safeguarding is spiritual wellbeing; an area that we will refer to in the discussion.

\subsubsection{Wishes}

Mostly in the Children Act 1989 and the Children Act 2004, but in three occasions in the Children and Social Work Act 2017, the term 'wishes' or phrase 'wishes, views and feelings' of the child and/or the child's parent(s) are considered. There is little differentiation of the way language has been used to describe this in the legislation, but what both the Children Act 1989 and the Children Act 2004 state is that wishes, as well as views and feelings, are considered to the best of the abilities of the assessor. In other words, the power, as found in this analysis already, is still assigned to the assessor, the service or the agency that mandate the assessment and are the deciding factor of when the input of children and parents is sufficient and fit for purpose.

\subsubsection{Harm}

Language used to refer to harmful outcomes often uses the term 'harm' and in phrases like 'risk of harm', 'risk of suffering harm', 'significant harm' and 'likelihood of harm'. Such language is mostly used in the Children Act 1989 and rarely in the Children Act 2004 and the Children and Social Work Act 2017. In the Children Act 1989, the term is defined as follows: 'harm means ill-treatment or the impairment of health or development [ F524including, for example, impairment suffered from seeing or hearing the ill-treatment of another];' (Children Act 1989, 31, 9B), while the Children and Social Work Act 2017, par.13(c.9)b specifies 'serious harm' as harm that 'includes serious or long-term impairment of mental health or intellectual, emotional, social or behavioural development'. This is a very important description that we come across the legislation as it complements the regulations and powers assigned by the Children Act 1989 but lacking the defining factors to assist with interpreting the material in practice. The Children Act 2004 discusses ‘bodily harm' (c.58(2)), putting emphasis on physical harm and the need for safeguarding individuals from such risks.

\subsubsection{Best interest}

The term 'best interest' is used only eight times in the Children Act 1989 and three more in the Children and Social Work Act 2017. On all occasions, the former refers to 'best interest' of the child when relaying provisions regarding decision-making, whether from a local authority or a court. In paragraphs 41,46 and 52, the legislation explicitly suggests that it is the local authority's and/or the responsible person's opinion that will determine whether a circumstance or decision is for the child's best interest. No further explanation is provided in that or other part of the Act. In the Children and Social Work Act 2017, the first time we come across the term 'best interest' is at the very beginning, in section 1, paragraph 1 , where the Act complements the statement with the need of local authorities to 'promote the physical and mental health and well-being' of children and young people (Children and Social Work Act 2017, 2017, par.1(1a)). The next two times we read about 'best interest' in the Act is in paragraph 49, where the regulations about courses for best interest assessors are relayed. 'Best interest' in these mentions, in other words, is describing the assessor's capacities rather than referring to the child or explaining the circumstances that constitute best interest.

\section{Discussion}

According to Shapiro (2011), jurisprudence, or otherwise the study of the law, is divided into two areas: normative and analytical. The former refers to the moralities that underpin the law and comprises interpretive and critical lenses of understanding its impact. In other words, the normative studies seek to explore whether there is logic underpinning the various provisions - in our study this would look like, 'Why our child protection law withdraws parental power'? The analytical area comprises the analyses of legal systems and their separation from other institutions, such as religion. When considering both these areas which Shapiro explains in depth in his book, we start realising the highly complex task of understanding the law and the language used to discuss it. That said, when exploring the vocabulary this study considered in its analysis, the question of morality becomes relevant, and so does the grey area of distinguishing between accountabilities provided in the law and responsibilities practised in the field of child protection and safeguarding.

Before unpicking this a little further, it is worth revisiting the structuring of the argument of this paper, in relation to the methodological queries which applied. Earlier in the 
methodology, we referred to the descriptors of the concept 'genre'. Following the reporting of the findings, we ought to highlight the below, too, which will help us develop a new discourse wherein we make sense of the findings and recognise ways forward. Genre is also defined as a 'staged, goal-oriented, purposeful activity in which speakers engage as members of our culture' (Martin, 1978, p.25). Alternatively, genres may be endless - as many as cultures, cultural interpretations of objects and their functions, as well as interpretive cultures. Eggins (2004) argued that language and vocabulary are used with a purpose, and this is linked to a given situation and culture. That said, language is the means to an end, but the mean is required to fit for purpose in the context in which it seeks to achieve an end point. The function or purpose of language changes based on the changes in both the context and the end. Image 1 depicts a metaphor that explains this and helps us appreciate the use of language in the Children Act 1989.

Image 1. Driving toward effective child protection and safeguarding

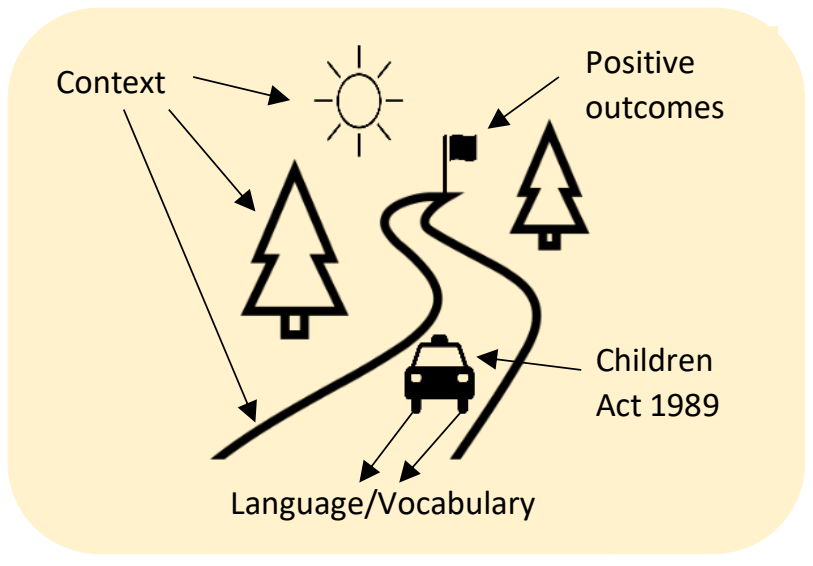

In this metaphor, we view a long road to positive outcomes. The Children Act (or any child protection and safeguarding legislation) is the vehicle that provides the framework which will guide us to the positive outcomes effective child protection and safeguarding. The vehicle is driving us through different contexts every time, however; there is the attempt to apply child protection and safeguarding legislation when working with younger children, older children, large families, in hospitals, in the community, with different cultures, religions, and so on. The context always differs, as the understanding of it and of those involved is different each time as well. Thus, the vehicle needs a set of tyres appropriate for the circumstances. The legislation is of the same significance, but the language used may need changes to accommodate the needs of everyone, but also facilitate clearer understanding of those applying the legislation. Particularly, the morality of the law that uses language which may oppose the original intent of the legislation can be questioned.

When examining the vocabulary and its semantics in child protection legislation, it quickly becomes clear that the legislation's intent is not to protect children but protect children from their parents/guardians. This is not a new idea or realisation. Ball (1998) went further to highlight the regulating of the very legal framework that controls parenthood in order to protect children. Much later, Morris and Featherstone (2010) offered the argument that in fact legislation that seeks to protect and safeguard children is contradictory, which is in line with the present conceptual content analysis. Legislation, on the one hand, is concerned with the responsibility of the parents/guardians to care, while, on the other hand, positions them as entities that fail, thus risking harm on their children.

This is reminiscent of the debates about parenthood (McClain and Cere, 2013) and specifically Plato's Republic, in which he argued the deconstruction of families as private spheres in order to alleviate parents from the burden of raising their children and give them the chance to achieve in other areas in life. The answer to that would be legislation and a system that can govern childhood which can be detached from the need for parents to be part of it. Of course, Plato's work alludes to something more extreme than what this analysis uncovers, yet an extremity that shares with some of the contradictions we see in the Children Act 1989, Children Act 2004, and Children and Social Work Act 2017. This study has found that the semantics of the language used allude to the framing of parents/guardians as villains. Without this frame, the morality (inclusive of justification) of child protection legislation is non-existent. Alternatively, child protection and safeguarding legislation is morally appropriate in the proviso that children need to be protected from someone. Legal provisions cannot simply hypothesise, thus target the group that is closest to the children it attempts to safeguard. Yet, the question with this is how we respond to the damaging effect this has on children. This question has also been posed by law experts Sankaran, Church and Mitchell (2018), who recognise that child protection services' most drastic intervention - that of removing children and causing family separation - inflicts damage on both children and their parents.

With that said, and drawing on the findings from the present analysis, the best interest of children may be morally underpinning legislation and adds to the factors informing decision-making (see Laming, 2009), but little is considered linguistically in legislation. This study shows that the concept of best interest is neither central nor adjacent to the allocated 
powers, provisions and responsibilities of the law. More studies in the past have made similar arguments, such as Eastmond and Ascher (2011), Coppins, Casey and Campbell (2011), and Tolonen, Koulu and Hakalehto (2019). Of course, such arguments must be made with caution as legislation provides the framework for practice in the field, but without a full analysis of the interpretation of this framework by those delivering it, we cannot have any conclusive thoughts.

Another area that this analysis raised was that of the concept of vulnerability. This concept is continuously discussed in the context of practice and policy and in relation to child protection and safeguarding (e.g. Keddell, 2018; Nadan and Korbin, 2018; Bessarab and Crawford, 2013; Sherwood-Johnson, 2013; Daniel, 2010; Fawcett, 2009; Appleton, 1994). Yet, it is not one that is either described in or regulated by the legal frameworks surrounding the child protection system. The language used in the legislation about child protection, in other words, and practice in child protection comprises gaps. Perhaps when looking at such gaps and in relation to the concept of failed families and parenthood, it is logical to wonder whether not referring to vulnerability is a strategy to avoid justifying failure of family life as a vulnerable moment, which would also require, morally that is, legal action for support and safeguarding (also see Reath, 1989).

Lastly, this analysis highlighted spiritual wellbeing as an area not evidently and thoroughly explored in child protection legislation. Crompton (2017) highlighted the necessary attention that religion and spiritual wellbeing of children demand in legislation in this area. The UN Convention on the Rights of the Child 1989 specifies that religion and spirituality are central to the welfare of the child, and the law, local government and professionals ought to safeguard children in this respect.

\section{Implications}

This analysis is merely a first step to start examining how the language used and the way it is used in child protection and safeguarding legislation in the UK influences its outcomes. With this analysis, we start identifying concepts that are explored in legislation, such as negative connotations of parenthood and control, which will help build more research that will examine how policy language is interpreted by different disciplines, agencies and services, and where the communication gaps emerge, which continuously lead to failings of the system and services as we described in the introduction of this paper.

In practice, and social work practice specifically, child protection and safeguarding are largely framed with the concepts of vulnerability, empowerment and resilience, among others. This analysis shows us the disconnect between legislation and practice; legislation's intentions are not to support individuals to develop resilience, nor the ideal of empowered children, while vulnerability is not discussed. Contradictorily, practice is underpinned by such principles and even though empowerment and resilience are two which enrich practice and facilitate better outcomes for children and their families, the concept of vulnerability undermines the work and proposes social work as an enabler of labelling and oppressive practice (for more on the challenges of neoliberal agendas in social work, see Rogowski, 2020).

The findings from this analysis can help identify gaps and initiate further research that can help develop informed additions to the child protection and safeguarding laws. An example is the demand for more culturally and religiously appropriate language in legislation, when this frames practice with a largely diverse and plural population.

\section{Conclusions}

This conceptual content analysis is a first step to exploring child protection and safeguarding language through the prism of social work practice. There is an undeniable need to focus on the gaps between practice and policy, and bridge those with research that can help inform decisions. As the image 1 shows us earlier in the paper, the road to positive outcomes is never the same. Language and its use can be powerful in the process as those help us navigate the different contexts every time. That said, policy makers and the government have the responsibility to ensure ongoing updates of the legislation in order to meet the continuously changing needs and demands of the population and society. Lastly, legislation must avoid the protection of some at the expense of others; something we observe in child protection and safeguarding law, wherein parents/guardians' failure is a prerequisite for the moral character of the documents reviewed for the purposes of this study.

\section{References}

Aldgate, J. and Stratham, J. (2001) The Children Act now: messages from research. Norwich: Stationery Office.

Appleton, J.V. (1994) 'The concept of vulnerability in relation to child protection: health visitors' perceptions', Journal of Advanced Nursing, 20(6), pp.1132-1140.

Ball, C., 1998. Regulating child care: from the Children Act 1948 to the present day. Child \& Family Social Work, 3(3), pp.163-171. 
Bessarab, D. and Crawford, F. (2013) 'Trauma, grief and loss: The vulnerability of Aboriginal families in the child protection system' in Bennett, B. and Green, S. (eds.) Our voices: Aboriginal and Torres Strait Islander social work. London, UK: Palgrave Macmillan.

Bhatia, V.K. (1993) Analyzing genre: language use in professional settings. London, UK: Longman.

Bryman, A. (2016) Social research methods. Oxford: Oxford University Press.

Cooper, A. and Whittaker, A. (2014) 'History as tragedy, never as farce: tracing the long cultural narrative of child protection in England', Journal of Social Work Practice, 28(3), pp.251-266.

Coppins, V., Casey, S. and Campbell, A. (2011) 'The child's best interest: a review of Australian juvenile justice legislation', The Open Criminology Journal, 4(1), pp.2331.

Crompton, M. (2017) Children, spirituality, religion and social work. London, UK: Routledge.

Daniel, B. (2010) 'Concepts of adversity, risk, vulnerability and resilience: a discussion in the context of the "child protection system', Social Policy and Society, 9(2), pp.231-241.

Department for Education (2018) Working together to safeguard children: a guide to inter-agency working to safeguard and promote the welfare of children. London, UK: Department for Education.

Department for Education (2013) Working together to safeguard children: a guide to inter-agency working to safeguard and promote the welfare of children. London, UK: Department for Education.

Eastmond, M. and Ascher, H. (2011) 'In the best interest of the child? The politics of vulnerability and negotiations for asylum in Sweden', Journal of Ethnic and Migration Studies, 37(8), pp.1185-1200.

Eggins, S. (2004) Introduction to systemic functional linguistics. New York, NY: A\&C Black.

Erlingsson, C. and Brysiewicz, P. (2017) A hands-on guide to doing content analysis. African Journal of Emergency Medicine, 7(3), pp.93-99.

Grey, D. (2009) More Ignorant and Stupid than Wilfully Cruel': Homicide Trials and 'Baby-Farming', in England and Wales in the Wake of the Children Act 1908.

Featherstone, B., Morris, K. and White, S. (2014) Reimagining child protection: Towards humane social work with families. Bristol: Policy Press.
Fawcett, B. (2009) 'Vulnerability: Questioning the certainties in social work and health', International Social Work, 52(4), 473-484.

Fraser, M.W., Galinsky, M.J. and Richman, J.M. (1999) 'Risk, protection, and resilience: Toward a conceptual framework for social work practice', Social Work Research, 23(3), pp.131-143.

Hall, C., Slembrouck, S. and Sarangi, S. (2020) Language practices in social work: Categorisation and accountability in child welfare. London, UK: Routledge.

IICSA (2018) Independent inquiry into child sexual abuse in England and Wales (IICSA). Available at: https://www.iicsa.org.uk/ (Accessed: 4 September 2021).

Jackson, K. and Bazeley, P. (2019) Qualitative data analysis with NVivo. London, UK: Sage.

Keddell, E. (2018) 'The vulnerable child in neoliberal contexts: The construction of children in the Aotearoa New Zealand child protection reforms', Childhood, 25(1), pp.93-108.

Klonowski, A. (2013) Report of the independent reviewing officer in relation to child sexual exploitation issues in Rochdale Metropolitan Borough Council during the period 2006 to 2013. Rochdale: Rochdale Metropolitan Borough.

Laming, H.B. (2009) The protection of children in England: A progress report (Vol. 330). Norwich: The Stationery Office.

Laming, H.B. (2003) The Victoria Climbie inquiry: report of an inquiry by Lord Laming. Norwich: The Stationary Office.

Martin, R. (1978) 'Expert and referent power: A framework for understanding and maximizing consultation effectiveness', Journal of School Psychology, 16(1), pp.49-55.

Martín Martín, P.Á. (2003) ‘A genre-analytic study of English and Spanish research article abstracts in the experimental social sciences', English for Specific Purposes, 22(1), pp. $25-43$.

McClain, L.C. and Cere, D. (eds.) (2013) What is parenthood?: contemporary debates about the family. New York, NY: NYU Press.

McFadden, P., Mallett, J., Campbell, A. and Taylor, B. (2019) 'Explaining self-reported resilience in child-protection social work: The role of organisational factors, demographic information and job characteristics', The British Journal of Social Work, 49(1), pp.198-216. 
Morris, K. and Featherstone, B. (2010) 'Investing in children, regulating parents, thinking family: a decade of tensions and contradictions', Social Policy and Society, 9(4), pp.557-566.

Munro, E. (2019) Effective child protection. London, UK: Sage.

Munro, E. (2011) A child-centred system. London, UK: Department for Education.

Nadan, Y. and Korbin, J. (2018) 'Cultural context, intersectionality, and child vulnerability', Childhood Vulnerability Journal, 1(1), pp.5-14.

Prasad, B.D. (2008) 'Content analysis', Research Methods for Social Work, 5, pp.1-20.

Reath, A. (1989) Kant's theory of moral sensibility. Respect for the moral law and the influence of inclination. Oxford: Oxford University Press.

Rogowski, S. (2020) Social work: The rise and fall of a profession? Bristol: Policy Press.

Sankaran, V., Church, C. and Mitchell, M. (2018) 'A cure worse than the disease: The impact of removal on children and their families', Marquette Law Review, 102(4), pp.1161-1194.

Shapiro, J. (2011) Legality. Boston, MA: Harvard University Press.

Sherwood-Johnson, F. (2013) "Constructions of 'vulnerability' in comparative perspective: Scottish protection policies and the trouble with 'adults at risk", Disability \& Society, 28(7), pp.908-921.

Swale, J.M. (1990) Genre analysis: English in academic and research settings. Cambridge: Cambridge University Press.

Thompson, K. (2016) Strengthening child protection: Sharing information in multi-agency settings. Bristol: Policy Press.

Tolonen, H., Koulu, S. and Hakalehto, S. (2019) Best Interests of the Child in Finnish Legislation and Doctrine: What Has Changed and What Remains the Same? in Haugli, T.,

Warner, J. (2015) The emotional politics of social work and child protection. Bristol: Policy Press.

Yin, R.K. (1984) Case study research: Design and methods. Beverly Hills, CA: Sage. 